\title{
Benign strictures of the cervical oesophagus
}

\author{
P. M. STELL \\ Department of Otolaryngology, University of Liverpool, E.N.T. Infirmary, Myrtle Street, Liverpool 7
}

Four patients with a stricture of the cervical oesophagus are described. The stricture was hard and fibrotic and usually involved at least $2 \mathrm{~cm}$ of the oesophagus; there was no obvious cause of these strictures. Its management is described, using a local skin flap to replace the stenosed segment. This condition does not appear to have been described before.

Unlike the thoracic oesophagus below it and the pharynx above it, the cervical oesophagus has excited little interest in the surgical literature. Indeed during the last 15 years, there have been few reports in the English literature on benign diseases of this part of the oesophagus.

\section{THE PATIENTS}

Four patients and the relevant findings are included in the Table. There was no history of an impacted foreign body in any patient.

The stricture in the three women (Table) was severe and extensive; its upper end was at or just below the cricopharyngeus, so that the stenoses did not affect the post-cricoid space. When examined with the oesophagoscope, the stricture was very tight and could only be dilated with difficulty, if at all ; because of the hardness of the stricture, all three were suspected of having carcinoma, until proved otherwise by repeated biopsy. A biopsy was difficult to obtain in all of them because the stricture could not be dilated sufficiently to allow an oesophagoscope to be passed through.

In the male patient, the stricture was soft and annular, and situated in the middle of the cervical oesophagus. It could be dilated easily by the oesophagoscope.
Radiography demonstrated the strictures in the first three patients to be 'string-like' and at least $\bar{z}$ $2 \mathrm{~cm}$ long.

The barium swallow of patient M.C. is shown $\stackrel{\rho}{\supset}$ (Fig. 1), from which it can be seen that the stric- $\overrightarrow{0}$

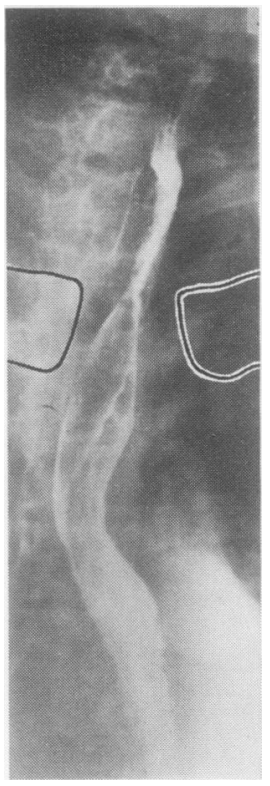

FIG. 1. Barium swallow of patient M.C. The clavicles have been marked to demonstrate the position of the stricture.

T A B L E

\begin{tabular}{|c|c|c|c|c|c|c|c|c|}
\hline Patient & Age & Sex & $\begin{array}{l}\text { Length of } \\
\text { History }\end{array}$ & Barium Swallow & $\begin{array}{l}\text { Distance from Upper End } \\
\text { of Stenosis to Upper } \\
\text { Incisor Teeth (cm) }\end{array}$ & W.R. & $\underset{\%}{\text { Haemoglobin }}$ & $\begin{array}{l}\text { Serum Iron } \\
(\mu \mathrm{g} / 100 \mathrm{ml})\end{array}$ \\
\hline $\begin{array}{l}\text { M.C. } \\
\text { C.D. }\end{array}$ & $\begin{array}{l}59 \\
70\end{array}$ & $\mathbf{F}$ & $\begin{array}{l}6 \mathrm{mth} \\
8 \mathrm{mth}\end{array}$ & $\begin{array}{l}\text { Stricture } \\
\text { Stricture and } \\
\text { sliding hiatus } \\
\text { hernia }\end{array}$ & $\begin{array}{l}17 \\
17\end{array}$ & $\begin{array}{c}\text { Negative } \\
,,\end{array}$ & $\begin{array}{l}95 \\
90\end{array}$ & $\begin{array}{c}263 \\
\text { Not done }\end{array}$ \\
\hline $\begin{array}{l}\text { M.H. } \\
\text { A.H. }\end{array}$ & $\begin{array}{l}68 \\
75\end{array}$ & $\underset{\mathbf{M}}{\mathbf{F}}$ & $\begin{array}{l}3 \mathrm{yr} \\
2 \mathrm{yr}\end{array}$ & $\begin{array}{l}\text { Stricture } \\
\text { Stricture }\end{array}$ & $\begin{array}{l}21 \\
18\end{array}$ & ,", & $\begin{array}{l}96 \\
94\end{array}$ & $\begin{array}{l}70 \\
82\end{array}$ \\
\hline
\end{tabular}


ture ends at clavicular level, that is, at the thoracic inlet.

\section{METHOD}

Dilatation was tried initially in all these patients but this was successful only in the male patient. Because of continuing dysphagia, weight loss, and inhalational pneumonia, operation was decided on in the other three patients. They were treated by Wookey's operation (1948). A large skin flap based laterally on the neck and crossing the midline by about $5 \mathrm{~cm}$ was raised. The cervical oesophagus was then exposed by dissection medial to the carotid sheath; the lobe of the thyroid gland was mobilized and displaced medially after the recurrent laryngeal nerve had been identified and preserved. The stricture of the oesophagus was then resected entirely, leaving a loss of continuity of 2 to $3 \mathrm{~cm}$. The superior and inferior edges of the skin flap were then stitched round the superior and inferior defects in the oesophagus to form a skin-lined gutter open laterally, which replaced the oesophageal stricture (Fig. 2). After an interval of approximately three weeks, the skin edges of the lateral fistula were divided and the fistula was closed by turning the edges in and stitching them. The resulting defect in the skin surface was then closed by a local rotation flap.

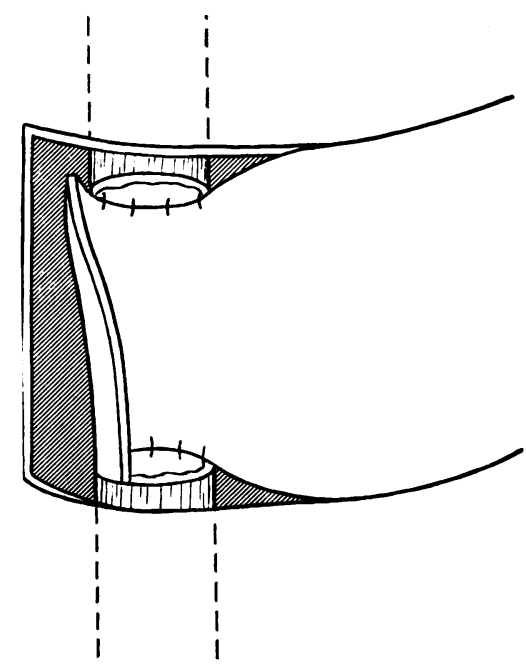

FIG. 2. Skin flap sutured into oesophageal defect.

\section{RESULTS}

One patient (C.D.) died three days after operation of a myocardial infarct. In patient M.C., swallowing is entirely satisfactory, but patient M.H. suffered a paralysis of the vocal cord leading to inhalation. This settled down after injec- tion of Teflon paste into the paralysed cord (Siegler, 1967). Two of the three patients thus had satisfactory swallowing restored.

\section{DISCUSSION}

Most of the diseases which cause strictures of the thoracic oesophagus do not appear to affect the cervical oesophagus. Thus congenital stenosis, which may or may not be associated with a tracheo-oesophageal fistula or due to congenital tracheobronchial remnants (Ishida, Tsuchida, Saito, and Tsunoda, 1969), affects the middle or lower third of the oesophagus. Caustic strictures are rarely seen in this country but occur fairly commonly in North America: Holinger, Johnston, Potts, and Dacunha (1954) reported 169. The postcricoid area of the pharynx and the lower third of the oesophagus are the sites most commonly affected; the cervical oesophagus appears to escape damage, however. The series of Holinger et al. also included postsurgical stenoses of the oesophagus following a variety of procedures, mainly intrathoracic. They described two patients with a stricture in the cervical area after thyroidectomy and seven after resection of a pharyngeal pouch. Strictures of the oesophagus associated with epidermolysis bullosa affect the cervical and upper oesophagus (Katz, Gryboski, Rosenbaum, and Spiro, 1967) in children with this rare disease of squamous epithelium, in which bulla formation is followed by scarring. Webs of the postcricoid space associated with the Paterson-Kelly syndrome (Kelly, 1919; Paterson, 1919) are well known, associated with anaemia, which may be microcytic or macrocytic (Jacobs and Kilpatrick, 1964). Webs do not affect the cervical oesophagus, however.

Peptic strictures usually affect the lower oesophagus, but if the oesophagus is partly lined by columnar epithelium, the stricture occurs at the junction of the columnar and squamous epithelium (Allison, 1970 ; Corrin, Harrison, and Johnson, 1970). Although the stricture can then be at any point in the oesophagus, peptic strictures of the cervical oesophagus do not appear to have been specifically recorded.

The biopsy and excisional specimens in these four patients were examined for evidence of columnar epithelium but all the specimens showed squamous epithelium only. The one patient with radiological evidence of hiatus hernia died, but necropsy was refused and the oesophagus was not available for study.

Although only one patient had a hiatus hernia, it is possible that the first three (M.C., C.D., 
and M.H.) of these strictures were peptic in origin. Examination of biopsy material and the strictures after resection shows that there was loss of the mucosa, with infiltration of the submucosa by lymphocytes, and extensive fibrosis. There was, however, no evidence of lymph nodes in the epithelium. These strictures were certainly not webs associated with the Paterson-Kelly syndrome as they did not affect the postcricoid space; they did not resemble webs endoscopically and the patients' haemoglobin and serum iron were normal.

If there are few references to the causes of stricture of the cervical oesophagus, there are even fewer concerning its management. One of the most recent was that of Erich in 1956, who replaced the cervical oesophagus by the larynx. This technique has not been accepted.

Although it is possible to replace the cervical oesophagus by a visceral transplant, such as stomach or colon, this appears to be an unnecessarily severe operation in this condition, requiring thoracotomy and laparotomy. The technique described here appears to be very much less traumatic, particularly as the patients are usually elderly. It is interesting that, although the entire circumference of the oesophagus is replaced by an aperistaltic segment of skin, the oesophagus still conducts food satisfactorily, provided that the larynx functions normally; presumably the base of the tongue provides sufficient thrust to carry the bolus past the segment lined by skin. During this stage the vocal cords must be able to approximate to protect the trachea from inhalation; this emphasizes the importance of identification and preservation of the recurrent laryngeal nerves.
The author is very grateful to Mr. F. Ronald Edwards for suggesting that these patients be recorded and for his help and patience in the preparation of this paper; and to those surgeons who referred these patients.

\section{REFERENCES}

Allison, P. R. (1970). Peptic oesophagitis and oesophageal $\overrightarrow{\vec{x}}$ stricture. Lancet, 2, 199.

Corrin, B., Harrison, G. K., and Johnson, H. R. M. (1970) High oesophageal stricture with hiatal hernia and a i lower esophagus lined by columnar epithelium. Thorax, of $25,89$.

Erich, J. B. (1956). Use of the larynx in repair of cicatricial $\stackrel{\circ}{工}$ stenosis of esophageal introitus. Trans. Amer. Laryng. Ass., 77, 218.

Holinger, P. H., Johnston, K. C., Potts, W. J., and Dacunha, F. (1954). Conservative and surgical management of benign strictures of the esophagus. J. thorac. Surg., 28, 345 .

Ishida, M., Tsuchida, Y., Saito, S., and Tsunoda, A. (1969). . Congenital esophageal stenosis due to tracheobronchial remnants. J. pediat. Surg., 4, 339.

Jacobs, A., and Kilpatrick, G. S. (1964). The Paterson-Kelly syndrome. Brit. med. J., $2,79$.

Katz, J., Gryboski, J. D., Rosenbaum, H. M., and Spiro, 气 H. M. (1967). Dysphagia in children with epidermolysis bullosa. Gastroenterology, 52, 259.

Kelly, A. B. (1919). Spasm at the entrance to the oesophagus. J. Laryng., 34, 285.

Paterson, D. R. (1919). A clinical type of dysphagia. $J$. Laryng., 34, 289.

Siegler, J. (1967). Rehabilitation of voice after recurrent laryngeal nerve paralysis using Teflon suspension. $J$. Laryng., 81, 1121.

Wookey, H. (1948). Surgical treatment of carcinoma of the hypopharynx and the oesophagus. Brit.J. Surg., 35, 249. 